\title{
Single umbilical artery: A case report
}

\author{
Neelam Pradhan and Raju Pradhan \\ Dept of Ob/Gyn TUTH, IOM \& Siddhi Polyclinic
}

\begin{abstract}
s
A 38 years woman pregnant for the second time was diagnosed as having a fetus with a single umbilical artery while undergoing routine ultrasound at 5 months of pregnancy. Reports of single umbilical artery associated with chromosomal abnormality are about $30 \%$. Luckily no abnormality was found at birth and thereafter in this baby.
\end{abstract}

Key words: single umbilical artery, USG diagnosis and chromosomal abnormality

\section{Introduction}

Presence of single umbilical artery has been found to be the most common vascular anomaly in humans. The incidence is seen to vary from $0.72 \%$ to $0.85 \%^{1,2}$ and are found more common in the twins with the presence of single artery in $5 \%$ of the cords of at least one twin. ${ }^{2}$ As the single vessel cord is found to be associated with congenital and chromosomal abnormalities, it is of great concern to the parents regarding well being of the baby and to the obstetrician with the management and how to counsel. The case of single umbilical artery is detected in the antenatal period more often nowadays due to routine anomaly scan advised in the second trimester. About $30 \%$ of all infants with only one umbilical artery had associated congenital anomalies. ${ }^{3}$ Bryan and Kohler ${ }^{1}$ had found $18 \%$ incidence of major malformations with a single umbilical artery, $34 \%$ were growth retarded and $17 \%$ delivered pre-term.

\section{Case}

A 38 yrs old $\mathrm{G}_{2} \mathrm{P}_{1}$, attended GOPD for ANC check up at 5 months of pregnancy. Her previous ANC check ups were being done at a private clinic. She had no problem during $1^{\text {st }}$ and $2^{\text {nd }}$ trimester of her pregnancy. On a routine USG advised at 5 months of pregnancy, showed a fetus of 23 wks with only 2 vessels in the cord, one artery and one vein (Fig.1). The rest of the fetal morphology were normal (Fig.2) while the placenta was anterior and low lying but free from the cervix. For this she had come to our hospital. The couple was explained about the risk of abnormality being associated and at same time was assured that since there were no congenital abnormalities and neither any abnormal soft tissue markers for associated chromosomal abnormalities

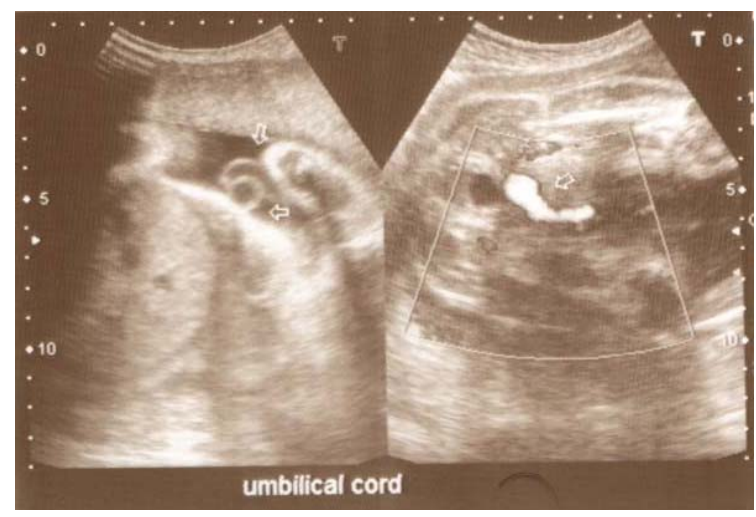

fig 1. umbilical cord with one artery and one vein

found during the ultrasound the chances of fetus being abnormal were low. So the couple decided to continue the pregnancy. An USG was done again at 31 wks as her previous scan had showed a low lying placenta, which was also normal with single umbilical artery

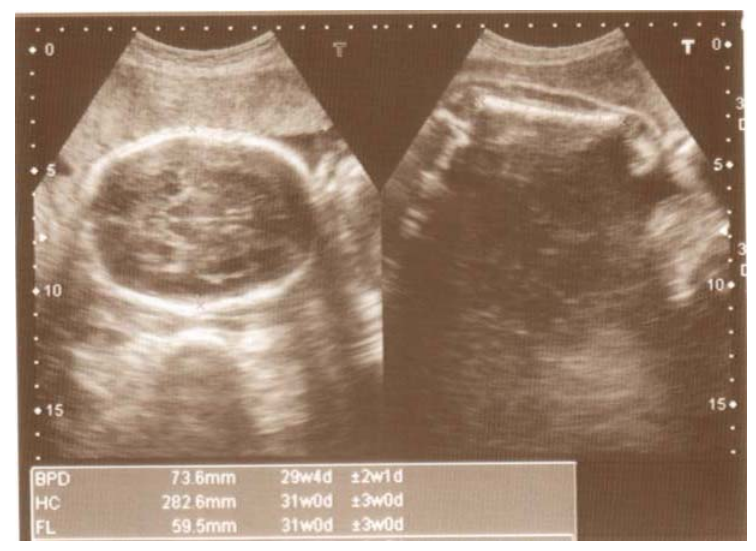

fig 2. normal fetal head fetal femur 
though the placenta was still slightly low lying. The growth was normal and the Doppler flow velocimetry was also normal. Her BP was raised to $140 / 90 \mathrm{~mm} \mathrm{Hg}$ on two occasions during the ANC visits at 35 wks and 37 wks. She also complained of decreased fetal movements twice at 37 wks of pregnancy, but the CTG was normal. She was admitted in the latent phase of labour at $38^{+4}$ weeks of gestation. Labour was augmented with 2.5 units of oxytocin in $5 \%$ dextrose. She delivered a healthy male baby weighing $3.4 \mathrm{~kg}$ with $7 / 10,8 / 10$ apgar score. The single umbilical artery was confirmed by naked eye examination of the cord after delivery. There was no gross congenital anomaly. The mother and the baby were discharged on next day. The baby is now more than a year old and has normal developmental mile stones.

\section{Discussion}

The umbilical cord serves as an essential conduit for oxygen and nutrients between mother and fetus. The cord normally inserts near the center of the placenta. Both fetal and placental cord insertions are generally well visualized by USG. The umbilical cord normally has two arteries and one vein. The right umbilical vein usually disappears early during fetal development, leaving only the original left vein. Color Doppler imaging may be helpful in identifying the number of vessels in the cord. Presence of single umbilical artery is the most common abnormality detected. This has been reported in $0.2 \%$ to $1.1 \%$ of deliveries or $2.7 \%$ to $12 \%$ of perinatal autopsies ${ }^{4}$. The higher incidence in autopsies indicate high frequency of anomalies in fetuses with single umbilical artery. The sonographic detection of a single umbilical artery should prompt a thorough evaluation of the fetus for associated abnormalities. The frequency of associated abnormalities reported varies from $25 \%$ to $50 \%$ in most studies. The malformations may involve multiple organs and may be minor or of major severity. It may be associated with chromosomal abnormality as well. Major anomaly included cardiac defects, holoprosencephaly, and hydrothorax. Large cisterna magna and diaphragmatic hernia. Importantly, none of the sonographically normal fetuses had a significant abnormality detected after birth. Parilla and colleagues reviewed 50 neonates with a two- vessel cord as an isolated finding on prenatal ultrasound. They reported that as an isolated finding a single umbilical artery was not associated with adverse outcomes. All 17 women who underwent amniocentesis had a fetus with normal karyotype.$^{5}$ However; Catanzarite cautioned that an isolated single umbilical artery may be associated with adverse outcomes. They reported two fetuses with lethal chromosomal abnormalities and a fetus who had tracheo-esophageal fistula out of 46 infants with a single umbilical artery. ${ }^{6}$ The investigators concluded that sonographic detection of a single umbilical artery in the absence of other abnormalities should not alter obstetric management but its identification should prompt a thorough evaluation for associated anomalies. If none are identified in experienced hands, then the outlook should generally be favourable as in this case. Detailed USG study done at 23 wks and 31 wks did not show any abnormality except single umbilical artery. The chromosomal studies of the fetus could not be done; as such investigation is not available yet in Nepal beside it being an invasive procedure with risks of its own. An isolated case of single umbilical artery without any associated other abnormalities, were reassuring to both the parents as well as the attending doctor of the fetus being well. So the pregnancy was continued taking chances of risk though remote and luckily the outcome was good.

\section{References}

1. Bryan EM, Kohler HG. The missing umbilical artery, 2 Paediatric follow up Arch Dis Child. 50:714, 1975

2. Benirschke K, Dodds JP. Angiomyxoma of the umbilical cord with atrophy of an umbilical artery: Obstet Gynecol 30:99, 1967.

3. Diseases and abnormalities of the placenta. In William's Obstetrics. Editors, FG Cunningham, PC MacDonald, NM Gant, KJ Leveno, LC Gilstrap, GDV Hankins and SL Clark. 20 $0^{\text {th }}$ edition, 1997, publisher Prentice-Hall International, INC, USA

4. Fox H. Pathology of the placenta, London. WB Saunders, 1978

5. Parilla BV, Tamura RK, MacGregor SN, Geibel LJ, Sabbagha RE. The clinical significance of single umbilical artery as an isolated finding on prenatal ultrasound. Obstet Gynecol 1995 85:570;

6. Catanzarite VA. The clinical significance of single umbilical artery as an isolated finding on prenatal ultrasound. Obstet Gynecol 1995 86:155. 